MATEC Web of Conferences 13,05003 (2014)

DOI: $10.1051 /$ matecconf/ 20141305003

(C) Owned by the authors, published by EDP Sciences, 2014

\title{
Studies on Steam Absorption Chillers Performance at a Cogeneration Plant
}

\author{
Mohd Amin Abd Majid ${ }^{1, a}$, Shaharin Anwar Sulaiman ${ }^{2}$, Tatsuo Fujii ${ }^{3}$, Naono ${ }^{4}$ \\ ${ }^{1,2}$ Department of Mechanical Engineering, Universiti Teknologi PETRONAS, Bandar Seri Iskandar, \\ 31750 Tronoh, Perak, Malaysia \\ ${ }^{3}$ Hitachi, Ltd., Hitachi Research Laboratory \\ ${ }^{4}$ Hitachi Asia Malaysia, R\&D Department
}

\begin{abstract}
Absorption chillers at cogeneration plants generate chilled water using steam supplied by heat recovery steam generators. The chillers can be of either single-effect or double effect configuration and the coefficient of performance (COP) depends on the selection made. The COP varies from 0.7 to 1.2 depending on the types of chillers. Single effect chillers normally have COP in the range of 0.68 to 0.79 . Double effect chillers COP are higher and can reach 1.2. However due to factors such as inappropriate operations and maintenance practices, COP could drop over a period of time. In this work the performances of double effect steam absorption chillers at a cogeneration plant were studied. The study revealed that during the period of eleven years of operation the COP of the chillers deteriorated from 1.25 to 0.6 . Regression models on the operation data indicated that the state of deterioration was projected to persist. Hence, it would be recommended that the chillers be considered for replacement since they had already undergone a series of costly repairs.
\end{abstract}

\section{Introduction}

Absorption chillers use heat as primary source of energy to provide cooling. Heat is used to drive the absorption cycle, as compared to mechanical power in vapour comperession chillers. The basic absorption cycle employs two fluids, the refrigerant and the absorbent. The most common refrigerant is water with lithium bromide as absorbent. In terms of performance, the coefficient of performance(COP) of absorption chillers are lower compared to mechanical chillers. Mroz [1] reported COP of single-effect absorption chillers between 0.4 to 0.8 . Higher range of COP between 0.73 to 0.79 was reported by Gomri [2]. Double-effect absorption chillers are about $40 \%$ more efficient than single effect absorption chillers [3]. Mroz [1] reported an average COP value of 0.69 from his study on single-effect absorption chillers of which the value was similar as that reported by Renewable Energy Institute [3]. The range of COP for absorption chillers reported by Herold [4] is wider covering from 0.7 to 1.2 . Single effect chillers are normally fed by heat input from steam or

\footnotetext{
${ }^{a}$ Corresponding author : mamin_amajid@petronas.com.my
}

This is an Open Access article distributed under the terms of the Creative Commons Attribution License 2.0, which permits unrestricted use, distribution, and reproduction in any medium, provided the original work is properly cited. 
hot water. Therefore, practical applications of single effect chillers are usually related to waste heat recovery from gas turbines. Typically the heat input temperatures must be greater than $75^{\circ} \mathrm{C}$. Available sizes range from 18 to $5840 \mathrm{~kW}$ (5 to 1660 tons of refrigeration) as the evaporator heat ransfer rate. The COP of the single effect chillers is approximately 0.7 [4]. One of the limitations of these chillers is that they cannot take advantage of availability of high temperature heat sources to achieve higher COP [3]. Double effect aborption chillers are used to take this advantage to achieve higher COP range of 1.0 to 1.2 [3]. Yin et al. [5] experimental measurement of double effect LiBr$\mathrm{H}_{2} \mathrm{O}$ steam-driven absorption chiller under various load conditions reported COP range of 0.7 to 1.0. The performance of chillers could deteriorate with time due to deterioration of absorber and generator [6]. The objective of this paper is to determine COP range of the chillers during the eleven years of the chillers life and establish the operability of the chillers. This was done by reviewing published and unpublished studies on steam driven $\mathrm{LiBr}-\mathrm{H}_{2} \mathrm{O}$ aborption chillers for a gas-fueled co-generation plant.

\section{Methodology}

The chillers considered in this study were steam absorption chillers (ACs) with 1250 RT capacity each as shown in Figure 1. The ACs were installed at a gas-fueled cogeneration plant at Univerasiti Techonologi PETRONAS, Seri Iskandar, Perak, Malaysia. The AC were driven by heat recovery steam generators (HRSG). Normally, the chillers were operated from 7 am to $11 \mathrm{pm}$ on weekdays. On week ends only one chiller was operated for eight hours.

The present study was performed based on published and unpublished studies on performances of the two ACs. The studies covered an operation period of eleven years. The findings of the study were used to formulate the replacement stategy for the two ACs. The steps consisted of critical review of the studies, further analysis of the relevant findings and comparison with design standards. This was later followed by establishment of replacement strategy.

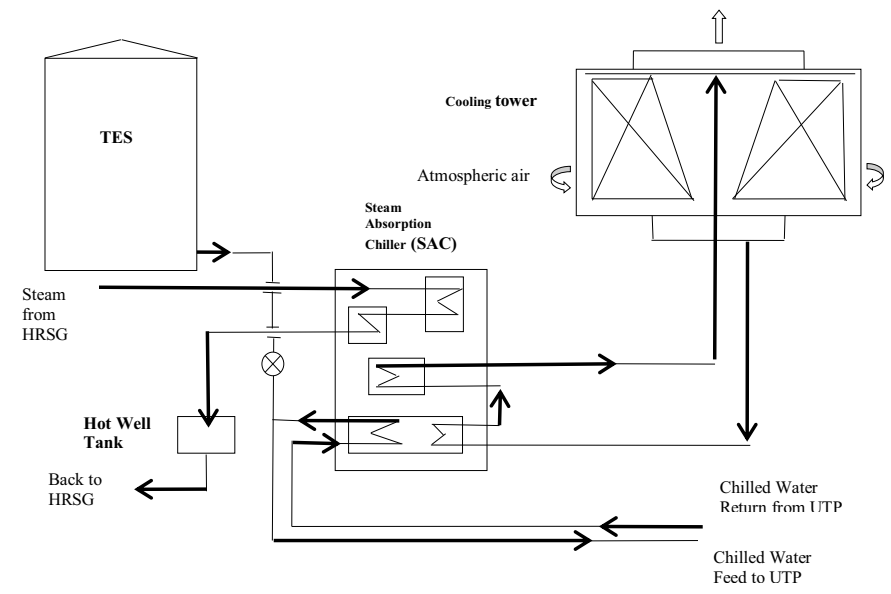

Figure 1. Process flow of steam absorption chiller system [8]

\subsection{SAC performance studies on the understudy chillers}

There were four reported studies on performance of the two ACs. Three of them were published and one was unpublished. The most recent unpublished study [6], covers data from 2003 to 2013. The published studies are by Gilani et al. [7], Rangkuti et al. [8] and Majid et al. [9]. Gilani et al. [7] and Rangkuti et al. [8] studies were based on 2005 data. The study by Majid et al. [9] was based on 2008 to 2012 data. 


\subsection{Coefficient of Performance (COP) Equations}

The equations used in the studies are listed in equations (1) and (3):

i. COP defined by [8]

$$
\begin{aligned}
& C O P=\frac{\text { Tons of refrigeration hour }(R T h)}{(\text { Steam Flow } / \text { hr }) \times(\text { Steam Enthalpy }- \text { SAC Drain Enthalpy })} \\
& C O P=\frac{\text { refrigeration }(\text { RTh })}{\text { steam }(\mathrm{kg}) \times(0.2189-0.0287)}
\end{aligned}
$$

Steam Enthalpy $=0.2189 \mathrm{RT} / \mathrm{kg}$ at $8.5 \mathrm{bar}$

Steam Absorption Chiller Drain $(90 \circledR \mathrm{C})=0.0287 \mathrm{RT} / \mathrm{kg}$

Equation (3) was used to evaluate the COP by [6].

$\mathrm{COP}=\mathrm{QE} / \mathrm{QG}$

$\mathrm{QE}$ is cooling heat (performance ) in $\mathrm{kW}$ and was evaluated using:

$V_{w} E$. (8) ${ }_{w} E \cdot c p_{w} E .\left(T_{w} E_{\text {in }}-T_{w} E_{\text {out }}\right)$.

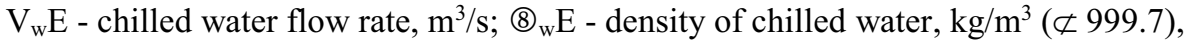

$\mathrm{cp}_{\mathrm{w}} \mathrm{E}$ : heat capacity of chilled water, $\left.\mathrm{kJ} /(\mathrm{kgK})\right)(\not \subset 4.192)$ and $\mathrm{TwE}$ is chilled water temperature, $\mathbb{R}_{\mathrm{C}}$.

QG is input heat (consumed energy) in $\mathrm{kW}$ and was evaluated using steam based calculation:

Gs.(hs - 4.1868.TSDL).

hs is Enthalpy of input steam, $\mathrm{kJ} / \mathrm{kg}$ and TSDL is Temperature of drain output, ${ }^{\circledR} \mathrm{C}$.

\section{Results and Discussions}

Study on the chillers by Gilani et al. [7] in 2005, reported COP for the two chillers:

i. COP of 1.2 for both chillers on 10th to 16th Jan 2005.

ii. COP of 1.19 and 1.0 for the two chillers on 11th to 17th April 2005.

iii. COP of 1.2 and 1.19 for the two chillers on 11th to 17th July 2005.

An average COP of 1.2 was also reported for both chillers on 22nd April 2005 by [8] (Figure 2).

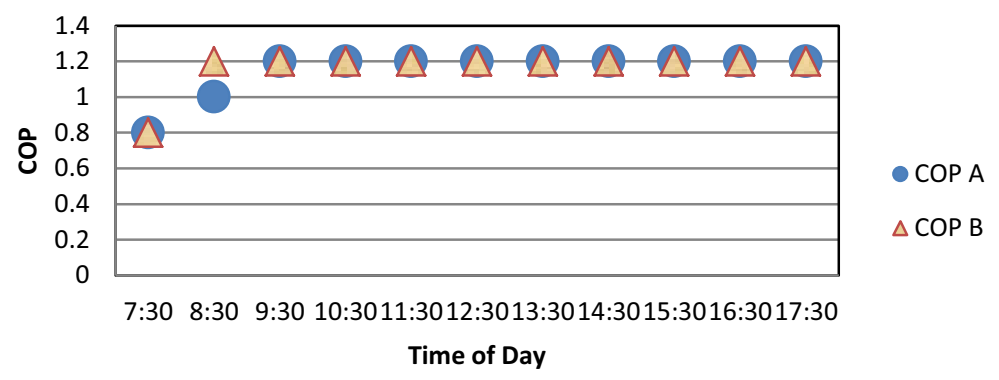

Figure 2. Hourly COP from 7.30am to $17.30 \mathrm{pm}$ of AC-A \&AC-B on 22/04/2005 [8]

Study by Majid et al. [9], reported that both chillers were operated at reduced capacity. However one of the chillers consumed steam as high as that needed to run a new chiller at full capacity (2012). 
The latest study conducted by Fujii [6]. This study focused on the performances of both ACs, which covered operations from 2003 up to 2013. Results on COP analysis for both the AC-A and AC-B are shown in Table 1. Plots of the results are shown in Fig. 3 and Fig. 4. The COP analysis was based on steam input to both ACs.

Table 1. COP of AC-A and AC-B from 2003 to 2013 [6]

\begin{tabular}{|l|l|l|l|l|l|l|l|l|l|l|l|}
\hline Year & 2003 & 2004 & 2005 & 2006 & 2007 & 2008 & 2009 & 2010 & 2011 & 2012 & 2013 \\
\hline COP AC-A & 1.25 & 1.20 & 1.10 & 1.20 & 1.10 & 0.90 & 0.85 & 0.75 & 0.80 & 0.85 & 0.75 \\
\hline COP AC-B & 1.25 & 1.20 & 1.10 & 1.20 & 1.15 & 1.00 & 0.90 & 0.85 & 0.80 & 0.70 & 0.60 \\
\hline
\end{tabular}

Figures 3 and 4 indicate very strong correlation between COP and years of operation. Both AC-A and $\mathrm{AC}-\mathrm{B}$ were displying deteriorating trend as seen from the trending equations. The COP performance of AC-A (Figure 3) was less than 0.8 from 2009. This was only seven years from installation year. However, COP AC-B started to drop below 0.8 since 2011 (Figure 4). The trend indicate that the $\mathrm{COP}$ would decrease further. The current state of deterioration had caused the COP values to decrease to 0.75 and 0.6 for $\mathrm{AC}-\mathrm{A}$ and $\mathrm{AC}-\mathrm{B}$ respectively. These values of $\mathrm{COP}$ are equivalent to COP for single effect chillers which indicate the chillers were performing below the design specification. The COP design specifications for both ACs were 1.19. These findings were also noted from the earlier study [8]. Hence both ACs would not be able to operate at desired COP. It is recommended that economic evaluation on utization of these ACs should be undertaken.

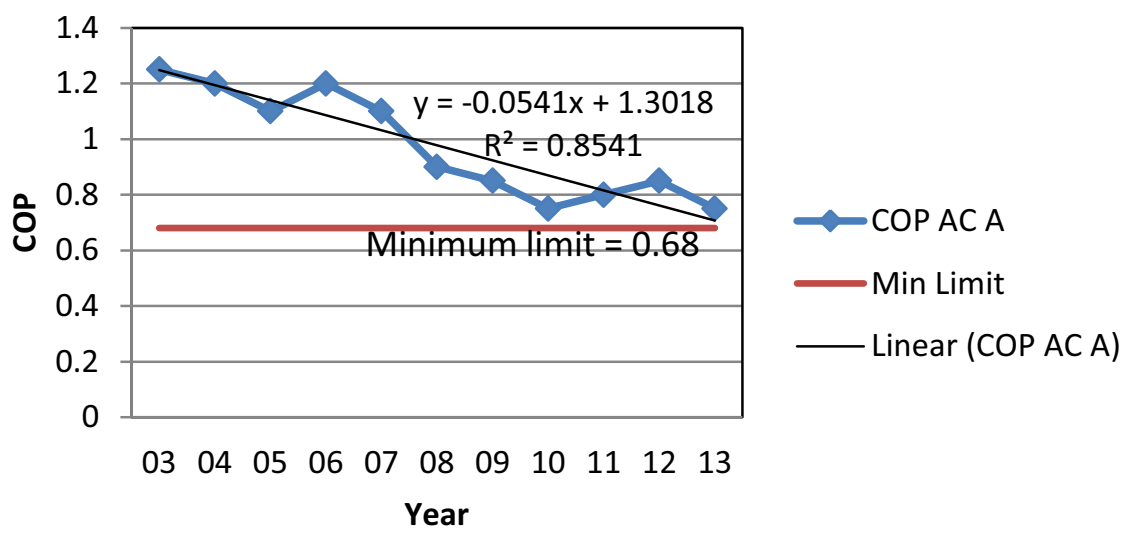

Figure 3. Plot of COP vs year for AC-A 


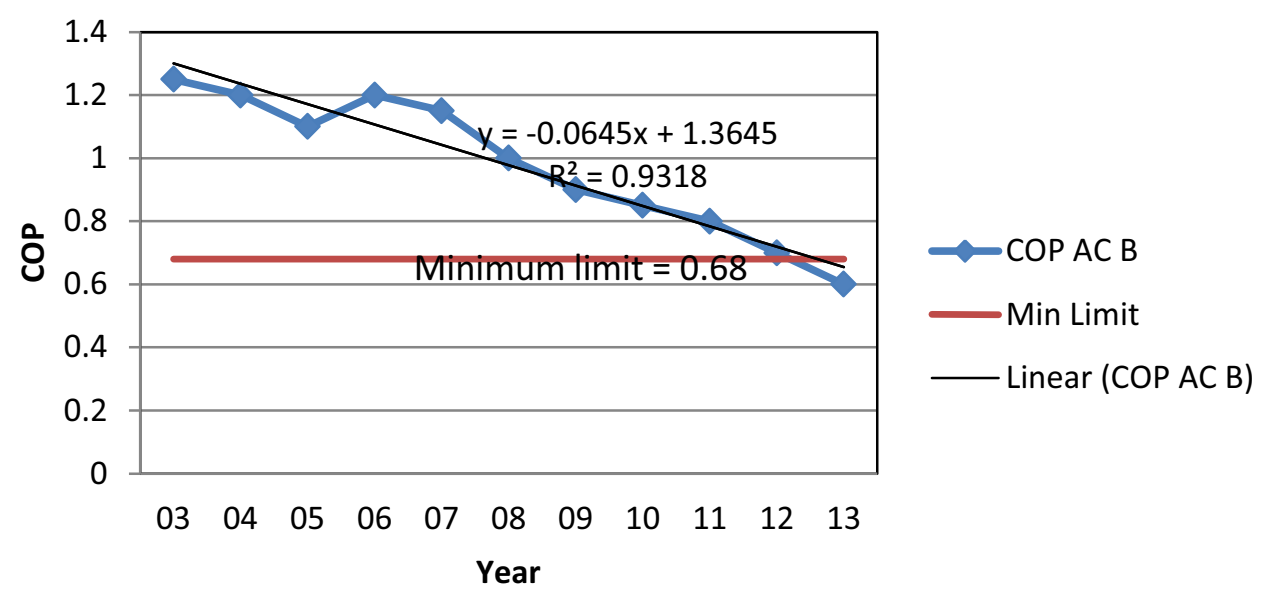

Figure 4. Plot of COP vs year for AC-B

\section{Conclusion}

The findings on the two units double effect $\mathrm{LiBr}-\mathrm{H}_{2} \mathrm{O}$ absorption chillers indicated that the $\mathrm{COP}$ of the chillers were 0.75 and 0.6 respectively. The second chiller was already below the minimum value of 0.68. The first chiller was not far from the minimum. Based on the trend, this chiller would also achieved COP of 0.68 within one to two years. These COP values were equivalent to COP of single effect chillers. The deterioation of performance of the chillers could be due to deterioration of absorbers and generators. Based from these findings, it would be recommended that both ACs be considered for replacement since they had undergone a series of costly repairs.

\section{Acknowledgement}

Author would like to thank Universiti Teknologi PETRONAS and Hitachi Ltd. for supporting this research study.

\section{References}

1. T. M. Mroz., Appl. Ther. Eng. 26, 2103-2109, (2006).

2. R. Gomri., Ener. Conv. and Manag. 51, 1629-1636, (2010).

3. REI, Reneawable Energy Institute, http://cogeneration.net/absorption-chillers/. retrieved on 29th Jan 2014.

4. K. E. Herold, R. Radermacher, S. A. Klein, Absorption Chillers and Heat Pumps (CRC Press USA, 1996).

5. H. Yin., M. QU, D. H. Archer, Appl. Ther. Eng. 30, 1741-1750, (2010).

6. Fuji T., Hitachi, Ltd., Hitachi Research Laboratory, Hitachi, Ltd. 2013, (to be published).

7. S. I. Gilani., M. A. A. Majid M. A., C. Rangkuti, Int. Conf. on Ener. and Env. 2006, Bangi Malaysia, (ICEE 2006).

8. C. Rangkuti., M. A. A. Majid, S. I. Gilani., Int. Conf. on Ener. and Env. 2006, Bangi, Malaysia, (ICEE 2006).

9. M. A. A. Majid, S. A. Sulaiman, H. Mokhtar H., A. L. Tamiru, Operating point estimation for an absorption process using data clustering technique. J. of Appl. Sc.,13(3), (2013). 